It might be objected that in the above proof we assume that the region $S^{\prime}$ around whose boundary we integrate lies within another region $S$, throughout which the conditions of continuity and the equation $(A)$ are satisfied. In the first place, however, this will be true in all cases to which we ordinarily apply the theorem; $*$ and in the second place the proof can easily be so modified as to obviate this difficulty, at least for all ordinary shapes of the boundary. All we should have to do would be by a slight extension of the method to prove the lemma given above, not for rectangles with sides parallel to the axes of $x$ and $y$, but for regions bounded by three sides of such a rectangle, and on the fourth side by a curve which is cut by no line parallel to the two parallel straight sides in more than one point. It will clearly be possible, in any ordinary case, to take the rectangles into which we cut up the region $S^{\prime}$ so small that the pieces of rectangles which occur near the boundary of $S^{\prime}$ shall be of this nature.

Harvard University, December, 1895.

\title{
NOTES.
}

A Regular meeting of the American Mathematical SoCIETY was held in New York, Saturday afternoon, January 25, at three o'clock, the President, Dr. Hins, in the chair. There were seventeen members present. One nomination for membership was received. The report of the auditing committee, appointed at the preceding meeting to examine the Treasurer's accounts, was presented and accepted. The following papers were read:

(1) Professor Henry S. White: "Kronecker's linear relation among the minors of a symmetric determinant."

(2) Professor H. TABer: "On certain sub-groups of the general projective group."

In the absence of Professor White his paper was read by Mr. Ling.

THE following mathematical courses are offered in the University of Leipzig for the summer semester of the present year :- Professor Scheibner: Theory of numbers;-Professor Neumann: Selected chapters in mathematical physics; Professor Lie: Theory of groups (continuous transformation groups);-Professor Mayer: Differential equations of dynam-

* The only case when it would not be true would be when the path of integration meets a natural boundary of the function we are integrating. 
ics;-Professor Engel: Ordinary differential equations;Dr. Scheffers: (1) Theory of surfaces; (2) Introduction to higher mathematies; - Dr. Hausdorff: (1) Analytic geometry; (2) Introduction to the mathematical theory of assurance. Owing to the illness of Professor Bruns, the astronomical courses have not yet been announced.

The number of mathematical students at Leipzig (not including those studying mathematics as a minor) is at present 42 ; last summer it was 37 , the preceding winter 25 .

The Royal Academy of Science and Letters of Denmark offers a gold medal to the author of a memoir containing a notable contribution to the solution of the following problem: To indicate the necessary and sufficient criterions to decide whether an algebraic equation with given numerical coefficients belongs, or does not belong, to the class of Abelian equations.

In presenting the question, it is stated that notwithstanding the great progress of algebra in modern times, with the exception of equations soluble by square roots, the problem to determine whether or not a given algebraic equation of unknown origin admits of solution, is to-day substantially where it was at the beginning of the century. However, it can hardly be doubted that the evolution of algebra during this epoch should render some advancement possible and furnish, in some cases at least, new methods of determining whether such an equation is of the class soluble through the extraction of roots.

Competitors should send their manuscripts before the end of October, 1896, to the Secretary of the Academy, Professor G. H. Zeuthen, of the University of Copenhagen. Decision will be rendered during the month of February following, after which authors may withdraw their memoirs.

\section{Report of the Treasurer for the Year 1895.}

The report which I have the honor to submit to you exhibits the receipts and disbursements for the year ending December 27, 1895.

In the receipts are included: 1st, the amounts received for dues and initiation fees for the year $1895 ; 2 d$, the amounts received for dues of previous years ; $3 d$, the amounts received for dues of the year 1896 ; 4 th, the amounts received from subscriptions to and sales of the Bulletin ; and 5th, the amounts received from subscriptions to fund for publication of papers presented at the Mathematical Congress of the Columbian Exposition.

The total receipts of the Society during the past year, as shown by the following itemized statement, amount to $\$ 1423.26$. The disbursements for the same period amount to $\$ 862.63$. The itemized vouchers for these disbursements are herewith submitted in Exhibit A.

The Society's present cash assets, including in these a total of $\$ 192.50$ of subscriptions to the publication fund mentioned above, on deposit in the Fifth Avenue Bank of New York, are $\$ 1677.30$. The net increase in assets during the past year is $\$ 560.63$.

NEw YoRk, December 27, 1895. 
The Treasurer in Account with the American Mathematical Society.

Dr. 1895.

Dec. 27.

To balance on hand Dec. $27,1894 \ldots \ldots \ldots \ldots \ldots$

To cash received for dues and initiation fees for the year ending Dec. 27, $1895 \ldots \ldots \ldots \ldots \ldots$.

To cash received for dues for the year $1893 \ldots \ldots$.

To cash received for dues for the year 1894......

To cash received for dues for the year 1896......

To cash received from subscriptions to and sales of the Bulletin...

To cash received from subscriptions to fund for publication of papers of Mathematical Congress of Columbian Exposition ................
1895.

Dec. 27.

By cash paid Macmillan \& Co. for publication of 8 numbers of Bulletin and extra copies thereof ...

By cash paid William $\mathbf{R}$. Jenkins for stamped envelopes ; for printing notices of meetings, cir-

85.00 culars, ballots, and tionery..............

20.00 By cash paid for expenses of publication committee, including clerical

119.50 assistance, postage, expressage, services of messengers, and telegrams............... By cash paid as contribution of American Mathematical Society to the New York Alliance of Scientific Societies..... By balance on deposit in the Fifth Avenue Bank of New York, N. Y ... 1677.30

\section{Report of Auditing Committee.}

The Committee finds that all sums entered as receipts in the Treasurer's books are properly accounted for by the balance remaining to the Society's credit in the bank and by proper vouchers for expenditures.

F. N. Cole,

J. B. Chittenden, Pomeroy Ladue.

New YoRK, January 25, 1896. 